\title{
DO PRESTÍGIO E DA CONSTRUÇÃO DA \\ IMORTALIDADE: OS SANJÛROKKASEN ATRAVÉS \\ DAS TRÊS PRIMEIRAS COLETÂNEAS IMPERIAIS E MAN'YÔSHÛ
}

Silvia Reis ${ }^{1}$

Resumo: Os Sanjûrokkasen de Fujiwara no Kintô é uma lista intrigante. Com trinta e seis poetas considerados por Kintô como exímios na composição poética, é possível, através da lista dos Sanjûrokkasen vislumbrar indícios da corte na Era Heian. Dado o status de Kintô como poeta e juiz de uta awase, a lista remete, em certa medida, ao imaginário da corte tanto quanto às suas preferências pessoais. Da mesma forma, as coletâneas imperiais nos fornecem evidências sobre quais poetas eram considerados dignos de terem seus poemas escolhidos - seja por talento ou por questões políticas - por seus pares ou gerações seguintes. Assim, tentando entender tal seleção que compõe os Sanjûrokkasen, foi mapeada e analisada a presença destes poetas nas três primeiras coleções imperiais, Kokinshû, Gosenshû e Shûishû, mais Man'yoshu.

Palavras-chave: Sanjûrokkasen, coleções imperiais, Fujiwara no Kintô

\begin{abstract}
Fujiwara no Kintô's Sanjûrokkasen is an intriguing list. With thirty six poets considered by Kintô as sages or genius in poetry composition, through the Sanjûrokkasen it's possible to catch glimpses of the Heian court at his age. Given Kintô's status as poet and uta awase judge, his list is in some way related to the court's imaginary as well as to his personal inclinations. In the same vein, the imperial collections supplies us with evidence about poets that were considered worthy to have their poetry selected - be it for talent or political reasons - by their peers or posterior generations. Nevertheless, trying to understand such list as the Sanjûrokkasen, their presence was analyzed in the first three imperial collections, Kokinshî, Gosenshû and Shûishû, plus Man'yoshu.
\end{abstract}

Keywords: Sanjûrokkasen, imperial collection, Fujiwara no Kintô

1 Grupo de Pesquisa Interdisciplinar de Estudos Japoneses, Museu Nacional, Universidade Federal do Rio de Janeiro. Contato: sreis@mn.ufrj.br 


\section{Introdução}

Fujiwara no Kintô (966-1041) foi um proeminente poeta e crítico na corte da Era Heian. Filho do regente, Kanpaku, Fujiwara no Yoritada, chegou à posição de Grande Conselheiro, Gondainagon, e ao segundo grau sênior, participando assim do núcleo político da corte sem, no entanto, chegar ao cargo de seu pai. Viveu justamente durante o ápice da presença da família Fujiwara na corte e no poder, tendo como regente Michinaga, e conviveu com renomadas figuras como Murasaki Shikibu e Sei Shônagon (HISAMATSU, 1982, p. 56-57). Do prestígio alcançado em participações em competições de poesia, uta awase, veio a ser apontado juiz nestas, posicionandose de forma privilegiada em relação à cultura da corte ${ }^{2}$. Segundo Teele (1976, p. 145), Kintô também era renomado calígrafo e flautista, além de compor com êxito poemas em chinês.

Kintô organizou uma coletânea de poemas exemplares, Kingyokushû (金玉集), Coletânea de ouro e jóias, e participou da organização da Shûi Wakashû, coletânea imperial concluída por volta de 1005 a 1011. Em 1024, dado seu gradual envolvimento com o Budismo, retirou-se da vida da corte. Em seu retiro em Nagatani (ao norte de Kyôto), ainda escreveu duas obras sobre composição de poesia, Shinsen Zuinô (新撰䯙 脳) e Waka Kuhon (和歌九品).

Ainda no ambiente da corte, Kintô organizou uma lista de trinta e seis poetas, os quais considerava exemplares em sua genialidade e habilidade, isto é, os Sanjûrokuninsen (三十六人撰) ou Sanjûrokkasen (三十六歌仙), Trinta e seis poetas exímios. Nessa coleção, a cada poeta listado acompanhavam alguns poemas. Tal lista tornouse famosa, sendo reproduzida, em várias versões ao longo do tempo (até a Era Edo), com ilustrações de cada poeta. A mais antiga conhecida é a Coletânea dos trinta e seis poetas, Sanjûrokuninshû (三十六人集), do século XII. No tocante aos rolos ilustrados, há ainda o Sanjûrokkasen emaki (三十六歌仙絵巻), em duas versões, a mais antiga conhecida como Satake (佐竹), e a segunda mais antiga como Agedatami (上畳), ambas do início do século XIII.

Assim, encontram-se listados poetas de outrora, anteriores ao registro de coletâneas de poesia, até poetas contemporâneos a Fujiwara no Kintô, a saber:

2 Como exemplo de seu impacto, pode ser citada uma passagem do diário de Murasaki Shikibu em que ela e outras damas sussurravam como deviam ter cuidado ao apresentarem seus poemas na frente de Kintô, tanto em relação ao poema per se quanto também na entonação correta ao declamá-lo (1996, p. 19). 
QUADRO 1: Os Sanjûrokkasen

\begin{tabular}{|c|c|c|}
\hline Kakinomoto no Hitomaro & 柿本人麻呂 & (final séc. VII - início séc. VIII) \\
\hline Ki no Tsurayuki & 紀貫之 & $(872-945)$ \\
\hline Ôshikôchi no Mitsune & 凡河内躬恒 & $( \pm 859 \pm 925)$ \\
\hline Ise & 伊勢 & (final séc. IX - início séc. X) \\
\hline Ôtomo no Yakamochi & 大伴家持 & (c. $718-785)$ \\
\hline Yamabe no Akahito & 山部赤人 & (c. Era Nara) \\
\hline Ariwara no Narihira & 在原業平 & $(825-880)$ \\
\hline Henjô & 僧正遍昭 & $(816-890)$ \\
\hline Sosei Hôshi & 素性法師 & (final séc. IX - início séc. X) \\
\hline Ki no Tomonori & 紀友則 & $( \pm 845-907)$ \\
\hline Sarumaru Dayu & 猿丸大夫 & (c. séc. IX) \\
\hline Ono no Komachi & 小野小町 & $( \pm 825 \pm 900)$ \\
\hline Fujiwara no Kanesuke & 藤原兼輔 & $(877-933)$ \\
\hline Fujiwara no Asatada & 藤原朝忠 & $(910-966)$ \\
\hline Fujiwara no Atsutada & 藤原敦忠 & $(906-943)$ \\
\hline Fujiwara no Takamitsu & 藤原高光 & (c. $939-994)$ \\
\hline Minamoto no Kintada & 源公忠 & $(889-948)$ \\
\hline Mibu no Tadamine & 壬生忠岑 & (final séc. IX - início séc. X) \\
\hline Kishi Joô & 徽子女王 & $(929-985)$ \\
\hline Ônakatomi no Yorimoto & 大中臣頼基 & $(886-958)$ \\
\hline Fujiwara no Toshiyuki & 藤原敏行 & $(?-901)$ \\
\hline Minamoto no Shigeyuki & 源重之 & $(? \pm 1000)$ \\
\hline Minamoto no Muneyuki & 源宗于 & $(?-939)$ \\
\hline Minamoto no Saneakira & 源信明 & $(910-970)$ \\
\hline Fujiwara no Nakafumi & 藤原仲文 & $(923-992)$ \\
\hline Ônakatomi no Yoshinobu & 大中臣能宣 & $(921-991)$ \\
\hline Mibu no Tadami & 壬生忠見 & (c. séc. X) \\
\hline Taira no Kanemori & 平兼盛 & $(?-990)$ \\
\hline Fujiwara no Kiyotada & 藤原清正 & (c. séc. X) \\
\hline Minamoto no Shitagô & 源順 & $(911-983)$ \\
\hline Fujiwara no Okikaze & 藤原興風 & (c. séc. X) \\
\hline
\end{tabular}




\begin{tabular}{|l|l|l|}
\hline Kiyohara no Motosuke & 清原元輔 & $(908-990)$ \\
\hline Sakanoue no Korenori & 坂上是則 & $(?-930)$ \\
\hline Fujiwara no Motozane & 藤原元真 & (c. séc. X) \\
Kodai no Kimi & 小大君 & (c. final do séc. X - séc. XI) \\
\hline Nakatsukasa & 中務 & $(912-991)$ \\
\hline
\end{tabular}

\section{Entre listas e coletâneas}

Com relação à lista dos Sanjûrokkasen é possível levantar vários questionamentos, dentre os quais a escolha de sua composição. No entanto, a intenção de Fujiwara no Kintô em tal listagem nos escapa, restando-nos indícios e pistas nos diversos registros de sua época e anteriores a esta. Desses, as coletâneas imperiais tem o potencial de servir de índice de prestígio, uma vez que, organizadas sob ordem imperial, eram de conhecimento da corte. Os poetas ali selecionados teriam a possibilidade de povoar o panteão dos grandes poetas no imaginário da corte, sendo admirados por seus pares e gerações posteriores. Assim, como a listagem começa com Kakinomoto no Hitomaro, famoso poeta antigo presente na Man'yôsh $\hat{u}$, adiciona-se esta coletânea à variável das coletâneas investigadas, a saber, Kokinshû, Gosenshî e Shûish û, conhecidas como Sandaishû, Coletâneas das três eras, produzidas até a elaboração da lista de Kintô.

Man'yôshû, Coletânea das dez mil folhas, é a mais antiga coletânea de poemas conhecida. Organizada por volta da Era Nara, contém aproximadamente 4.530 poemas, abrangendo desde poetas de época incerta, e desconhecidos, a poetas de renome, principalmente do período de 600 a 759 , sendo 759 correspondente ao último poema passível de datação. Segundo Miner et al. (1988, p. 192), Ôtomo no Yakamochi teria sido o último a trabalhar em sua organização. Do mesmo modo, os autores apontam para a interpretação cronológica da coletânea em quatro períodos: o primeiro começando em época lendária (por volta de 456), perpassando os reinados de Yômei, Saimei e Tenji, até a Reforma Taika (645) e a época de Fujiwara no Kamatari; o segundo período corresponderia ao final do século VII, no qual se localiza a produção de Kakinomoto no Hitomaro, um dos grandes poetas presentes nessa coleção; o terceiro período seria o início do século VIII, com a presença de poetas como Yamabe no Akahito e Ôtomo no Tabito e, no quarto período, aproximadamente entre 730 a 759 , seria o momento de finalização e proeminência de Ôtomo no Yakamochi.

Dividida em vinte livros, Man'yôsh û viria a se tornar um dos modelos a ser aplicado nas coletâneas imperiais. Destas, a primeira a ser finalizada entre 914 e 920 , sob ordem do imperador Daigo, foi a Kokin Wakashû, Coletânea de antigos e novos poemas. Com 1.111 poemas em vinte livros, também veio a ser o modelo no tocante ao conteúdo, dividido em temas: das estações do ano (Primavera, Verão, Outono e 
Inverno), a congratulações, despedidas, viagens, acrósticos, poemas de amor, lamentos, poemas de tópicos diversos e, por fim, no último livro, poemas tradicionais e rituais. Foi organizada por Ki no Tsurayuki (responsável também pelo prefácio em japonês), Ki no Tomonori, Ôshikôchi no Mitsune e Mibu no Tadamine. Além de um prefácio em japonês, acompanha um prefácio em chinês de Ki no Yoshimochi, similar ao de Tsurayuki.

A segunda coletânea imperial, Gosen Wakashû, Coletânea tardia de poemas, com 1.426 poemas (em vinte livros, sem prefácio), foi organizada sob ordem do imperador Murakami, por volta de 951. Todavia, o material selecionado teria sido o que ficou de fora da Kokinsh $\hat{u}$, e parte das descrições que acompanham os poemas seria fictícia (BROWER \& MINER, 1988, p.483). Sua organização foi de responsabilidade de Ônakatomi no Yoshinobu, Kiyohara no Motosuke, Minamoto no Shitagô, Ki no Tokibumi e Sakanoue no Mochiki, conhecidos como Nashitsubo no gonin (梨壶の五 人), Os Cinco do Salão Pote de Pêra.

Shûi Wakashî, Coletânea de poemas colhidos, terceira coletânea imperial, organizada sob ordem do imperador reformado, daijô tennô (太上天皇), Kazan (花山), é composta por 1.351 poemas, em vinte livros, sem prefácio. Antes de sua conclusão, a mesma teria circulado pela corte em forma de rascunho, conhecido como Shûishô (拾遺 抄). Fujiwara no Kintô é apontado como organizador principal, porém, Kazan teria se envolvido diretamente na compilação dos poemas, revisando e dando a palavra final no conteúdo da coletânea (MINER et al., 1988, p. 150; TAKAMORI, 2008, p. 159-160).

Para análise das coletâneas mencionadas, foram usadas as transcrições disponíveis no Japanese Text Initiative, biblioteca digital criada e mantida pelo Centro de Textos Eletrônicos da Biblioteca da Universidade de Virgínia e Biblioteca do Leste Asiático da Universidade de Pittsburgh, e no site de Kokugo e Kokubungaku do Prof. Shibuya Eiichi, da Universidade Takachiho.

\section{Os Poetas Imortalizados}

No Quadro 2 são apresentados os Sanjûrokkasen em ordem cronológica, segundo as datas conhecidas e algumas supostas, de forma a agrupar relações e desenhar claramente contemporaneidades e seqüências (em termos de família e gerações) frente às coletâneas Man'yôshî, Kokinshû, Gosenshû e Shûish $\hat{u}$. Destarte, buscou-se mapear as presenças e ausências destes poetas nas coletâneas mencionadas: 
QUADRO 2: Os Sanjûrokkasen e seus poemas na Man'yôsh $\hat{u}$ e na Sandaish $\hat{u}^{3}$

\begin{tabular}{|c|c|c|c|c|}
\hline & \begin{tabular}{|c|} 
Man'yôshû \\
$(+759)$ \\
\end{tabular} & $\begin{array}{l}\text { Kokinshû } \\
\text { (914-920) }\end{array}$ & $\begin{array}{c}\text { Gosenshû } \\
\text { (951) } \\
\end{array}$ & $\begin{array}{c}\text { Shûishû } \\
(1005-1011)\end{array}$ \\
\hline $\begin{array}{l}\text { Kakinomoto no Hitomaro } \\
\text { (final séc. VII - início séc. VIII) }\end{array}$ & 500 & - & - & 103 \\
\hline Yamabe no Akahito (c. Era Nara) & 50 & - & - & 3 \\
\hline Ôtomo no Yakamochi (c. 718 - 785) & 473 & - & - & 3 \\
\hline Sarumaru (c. séc. IX) & - & - & - & - \\
\hline Henjô (816-890) & - & 17 & 5 & 4 \\
\hline Ariwara no Narihira $(825-880)$ & - & 30 & 10 & 3 \\
\hline Ono no Komachi $( \pm 825 \pm 900)$ & - & 18 & 4 & - \\
\hline Ki no Tomonori $( \pm 845-907)$ & - & 46 & 9 & 2 \\
\hline Ôshikôchi no Mitsune $( \pm 859+925)$ & - & 60 & 23 & 34 \\
\hline Ki no Tsurayuki (872-945) & - & 102 & 81 ou $74^{4}$ & 107 \\
\hline $\begin{array}{l}\text { Mibu no Tadamine } \\
\text { (final séc. IX - início séc. X) }\end{array}$ & - & 36 & 10 & 12 \\
\hline Fujiwara no Kanesuke $(877-933)$ & - & 4 & 22 & - \\
\hline Fujiwara no Toshiyuki $(?-901)$ & - & 19 & 4 & - \\
\hline Ise (final séc. IX - início séc. X) & - & 22 & 70 & 25 \\
\hline $\begin{array}{l}\text { Sosei Hôshi (final séc. IX - } \\
\text { início séc. X) }\end{array}$ & - & 37 & 7 & 2 \\
\hline Sakanoue no Korenori $(?-930)$ & - & 8 & 6 & 3 \\
\hline Minamoto no Muneyuki (? - 939) & - & 8 & 2 & - \\
\hline Fujiwara no Okikaze (c. séc. X) & - & 17 & 5 & - \\
\hline Fujiwara no Kiyotada (c. séc. X) & - & - & 9 & 3 \\
\hline Ônakatomi no Yorimoto $(886-958)$ & - & - & - & 2 \\
\hline Minamoto no Kintada $(889-948)$ & - & - & 2 & 4 \\
\hline Mibu no Tadami (c. séc. X) & - & - & 1 & 14 \\
\hline Fujiwara no Atsutada (906 - 943) & - & - & 10 & 5 \\
\hline Kiyohara no Motosuke $(908-990)$ & - & - & 1 & 48 \\
\hline
\end{tabular}

3 Levantamento realizado segundo autorias atribuídas aos poemas das respectivas coletâneas nas transcrições do Japanese Text Initiative e do Prof. Shibuya Eiichi, e o estudo realizado por Tsuji (1991).

4 Há uma variação na contagem do total de poemas de Tsurayuki devido ao grupo de poemas 255 a 261, marcados como de autoria desconhecida em algumas transcrições e atribuído a ele em outras. 


\begin{tabular}{|c|c|c|c|c|}
\hline Fujiwara no Asatada $(910-966)$ & - & - & 4 & 3 \\
\hline Minamoto no Saneakira $(910-970)$ & - & - & 5 & 1 \\
\hline Minamoto no Shitagô (911 - 983) & - & - & - & 27 \\
\hline Taira no Kanemori $(?-990)$ & - & - & 2 & 38 \\
\hline Nakatsukasa $(912-991)$ & - & - & 7 & 18 \\
\hline Ônakatomi no Yoshinobu (921 - 991) & - & - & - & 59 \\
\hline Fujiwara no Nakafumi (923 - 992) & - & - & - & 3 \\
\hline Kishi Joô (929 - 985) & - & - & - & 5 \\
\hline Fujiwara no Takamitsu (c. 939 - 994) & - & - & - & 4 \\
\hline Fujiwara no Motozane (c. séc. X) & - & - & - & - \\
\hline Minamoto no Shigeyuki $(? \pm 1000)$ & - & - & - & 13 \\
\hline $\begin{array}{l}\text { Kodai no Kimi (c. final do séc. X- } \\
\text { séc. XI) }\end{array}$ & - & - & - & 2 \\
\hline
\end{tabular}

Kakinomoto no Hitomaro aparece como um dos grandes poetas na Man'yôshû, reverberando da mesma forma na Shûish $\hat{u}$. No entanto, de sua produção presente na Man'yôshû, por volta de 90 poemas seriam realmente dele (MINER et al., 1988). Grande parte dos poemas de autoria duvidosa contém no tópico a informação de fazerem parte de um Hitomaro Kashû, uma coleção atribuída a ele. Segundo Miner et al. $(1988$, p. 175) a qualidade dos poemas varia muito, enquanto alguns parecem ser precisamente de Hitomaro, outros em nada se assemelham ao seu estilo e habilidade. Dado o seu prestígio, não seria estranho que poemas fossem atribuídos ao seu nome. De fato, os poemas marcados como sendo dessa coleção encontram-se nos últimos livros da Man'yôshû, ao passo que os poemas de autoria não questionada se encontram nos primeiros livros. Segundo Wada (2006), uma das principais funções de Hitomaro como poeta da corte era compor sobre o caráter divino da família imperial, elevando-o a uma dimensão estética.

Yamabe no Akahito é também um dos principais poetas da Man'yôshĥ, mesmo não tendo a presença de Hitomaro. Todavia, no prefácio em japonês da Kokinsh $\hat{u}$, ambos são colocados no mesmo patamar por Ki no Tsurayuki, pois Hitomaro não poderia ser colocado acima de Akahito, da mesma forma que este não poderia ser colocado abaixo de Hitomaro ${ }^{5}$

Ôtomo no Yakamochi também tem forte presença na Man'yôshû, além de ter participado como compilador final desta. Da mesma forma que Hitomaro e Akahito, só volta a aparecer na Shûish $\hat{u}$. No entanto, ao contrário dos dois, Yakamochi não é mencionado no prefácio da Kokinsh $\hat{u}$. No final do prefácio, Tsurayuki detalha o

5 Na transcrição lê-se: “(...) 人まろはあかひとがかみにたたむことかたく、あか人は人まろがし もにたたむことかたくなむありける（. . . )”(Kokinshû, in: Japanese Text Initiative). 
contexto de produção da coletânea e de como foram ordenados a apresentar poemas antigos não incluídos na Man'yôsh $\hat{u}$, aliados a poemas de autoria própria. Assim, fica clara a ausência dos três na Kokinshû. Não obstante, seis poemas, 135, 211, 334, 409, 621 e 907, de autoria desconhecida, são acompanhados da anotação: sobre esse poema, alguns dizem que foi composto por Kakinomoto no Hitomaro ${ }^{6}$.

De Ariwara no Narihira, sabe-se mais sobre a lenda do que sobre o homem, principalmente pelo famoso Ise Monogatari ${ }^{7}$, no qual o principal personagem teria sido espelhado em Narihira. Cerca de 35 poemas podem ser identificados como sendo de sua autoria, reforçando, segundo Miner et al. (1988, p. 169), o paralelo entre os casos amorosos do personagem e o nobre de outrora, Narihira, e, com isso, a lenda. Também é mencionado no prefácio da Kokinsh $\hat{u}$, que Tsurayuki compara sua poesia ao de flores murchas que perderam sua cor mas ainda exalam seu perfume, pois apesar de intensa em emoção faltava o vicejar das palavras. Quinto filho do príncipe Abo (este, filho do imperador Heizei) e da princesa Ito (filha do imperador Kammu), foi retirado da família imperial e lhe dado sobrenome, Ariwara (HISAMATSU, 1982, p. 54).

A vida de Ono no Komachi também é cercada de lendas. Segundo Strong (1994, p. 392), a primeira menção de que se tem notícia sobre Komachi é feita no prefácio da Kokinshû. Um de seus poemas mais controversos também é reproduzido em Ise Monogatari, logo após um poema de Narihira, sugerindo uma ligação que talvez de fato não teria existido. Tal poema, de número 623 , é acompanhado da notação de tópico desconhecido. O poema de Narihira é o de número 622, precedendo o de Komachi na Kokinsh û, porém, diferentemente do que o ocorre em Ise Monogatari, este poema também é de tópico desconhecido. Em Ise Monogatari, ambos os poemas são precedidos de introduções que os ligam, o de Narihira, que existira um homem que enviou tal poema a uma mulher que não tinha dito se o encontraria, e em seguida o de Komachi, que teria respondido a mulher, a qual conhecia bem o amor ${ }^{8}$. Esse poema de Komachi é rico em ambigüidades, principalmente pelo uso de várias kakekotoba e pode ser interpretado, principalmente, de duas maneiras, uma na qual ridiculariza as pretensões desse homem que não teria a menor chance com ela, mas não percebe isso, e outra em que ela lamentaria a incapacidade dele de perceber seu pesar (STRONG, 1994, p. 394-395).

Parte da lenda que cerca Komachi é justamente de que teria sido uma mulher bela, mas fria e cruel. Não obstante, seus poemas presentes nas coletâneas imperiais iniciais pouco ou nada corroborariam essa caracterização. Dentre aqueles com quem de fato trocou poemas figuram Henjô e Ôchikôchi no Mitsune, ambos presentes também na lista dos Sanjûrokkasen. Pouco se sabe sobre Henjô, monge budista e poeta consagrado,

6ここうたは、ある人のいはく、柿本人麿が哥也” (Kokinshû, in: Japanese Text Initiative).

7 Concluído em meados da Era Heian, pouco depois da finalização da Kokinshû (Miner et al, 1988, p. 169; Takayanagi et al., 1974, p. 62).

8 “いろごのみなる女、返し”(Ise Monogatari, Episódio 25 in: Japanese Initiative Text). 
além de ser mencionado por Tsurayuki no prefácio da Kokinsh $\hat{u}$. De sua troca de poemas com Komachi tem-se a indicação de um caso entre os dois em Yamato Monogatari, o qual Miner et al. (1988, p. 163) aponta como sendo ficcional. Sosei, filho de Henjô, também tornou-se monge budista e figura como parte dos Sanjûrokkasen, ao mesmo tempo em que supera seu pai no tocante à quantidade de poemas seus presentes nas três primeiras coletâneas imperiais, principalmente na Kokinsh $\hat{u}$, com 37 poemas contra 17 de Henjô.

Os quatro responsáveis pela compilação da Kokinshû figuram na lista dos Sanjûrokkasen, dentre os quais Ki no Tsurayuki aparece como o principal poeta com 102 poemas, seguido de Ôshikôchi no Mitsune, Ki no Tomonori e Mibu no Tadamine. Ao longo das demais coletâneas aqui estudadas, a diferença de quantidade entre seus poemas permanece, com exceção de Tomonori, que acaba por ser superado por Tadamine na Shûish $\hat{u}$. De qualquer forma, a constante presença ao longo desse período corrobora o prestígio atribuído a eles.

Como autor do prefácio da Kokinsh $\hat{u}$, Ki no Tsurayuki surge como um dos primeiros críticos de waka de que se tem notícia. Também é o autor do Tosa Nikki, um dos primeiros diários literários. Escrito pela perspectiva de uma mulher, narra sua experiência como parte da comitiva de viagem de um governador que deixa Tosa, retornando à capital. De acordo com Miner et al. (1988, p. 183), o diário teria sido produzido por volta de 935, ao passo que Tsurayuki teria feito essa mesma viagem em 934. Era admirado por seus contemporâneos em sua habilidade como poeta tanto de waka quanto de poesia chinesa, e como crítico e homem culto.

Pouco se sabe sobre Ki no Tomonori, filho de Ki no Aritomo e primo de Tsurayuki, mas seus poemas estão presentes nas três coletâneas. Sabe-se que faleceu antes da conclusão da Kokinsh û, uma vez que consta um poema de Tsurayuki, de número 838, lamentando sua morte. Ôshikôchi Mitsune, por sua vez, foi governador de Kai, Izumi e Awaji. Em sua estada na corte participou da compilação da Kokinshû e era conhecido por seu talento em uta awase. É um dos poetas cujos poemas consistentemente aparecem em maior quantidade nas Sandaish $\hat{u}$.

Mibu no Tadamine, por sua vez, ganhou proeminência em uta awase, particularmente na Competição de poesia da casa do príncipe Koresada (是貞のみこ の家の哥合). Desta competição constam seis poema de sua autoria, 194, 214, 258, 263, 296 e 306, na Kokinshû. Ainda há a obra Wakatei Jusshu, Dez estilos de waka (和歌体 十種), sobre composição de poesia, de grande influência (HISAMATSU, 1982, p. 72; MINER et al., 1988, p. 197). No tocante a trocas de poemas, ele as fez com Tsurayuki, Mitsune e Ariwara no Shigeharu, filho de Narihira. Seu próprio filho, Mibu no Tadami, encontra-se entre os Sanjûrokkasen, com apenas um poema na Gosenshî e 14 poemas na Shûishû.

Voltando à Competição de poesia da casa do príncipe Koresada, Ki no Tomonori tem dois poemas presentes na Kokinshû, 207 e 270, assim como Fujiwara no Toshiyuki, com seis poemas dessa ocasião, 197, 218, 228, 239, 257 e 295. Toshiyuki era renomado 
calígrafo e participou de diversas uta awase, das quais a do príncipe Koresada é uma das mais famosas.

Fujiwara no Kanesuke, tataravô de Murasaki Shikibu, era conhecido como Tsutsumi Chûnagon (堤中納言), por seu cargo como conselheiro, chûnagon, e por sua residência próxima ao rio Kamo, na qual vários poetas renomados se encontravam, como Tsurayuki e Mitsune. Seu filho, Kiyotada, também incluído junto aos Sanjûrokkasen, ocupou diversos cargo no sistema Ritsuryô, dentre os quais Kurôdo (蔵人), e teria participado ativamente da vida literária da corte (ASAHI, 2016).

Ise era filha de Fujiwara no Tsugikage, governador de Ise - conhecida apenas por esse epíteto derivado do cargo de seu pai. Tanto seu tio Hirokage quanto seu primo Shigetoki ocuparam o cargo de diretor da universidade imperial, daigaku no kami. Reconhecida como poetisa, participou de uma famosa uta awase, Teiji no in utaawase, em 913, que contou com a participação de Tsurayuki e Mitsune, e diversos de seus poemas estão presentes nas três coletâneas. Foi dama de companhia da imperatriz Onshi, consorte do imperador Uda, e envolveu-se com o irmão mais velho desta, Fujiwara no Nakahira. Do malogro dessa união, diz-se que passou a rejeitar pretendentes. Acabou por se envolver com Uda, do qual teve um filho que faleceu aos sete anos. Segundo Hisamatsu (1982, p. 62), Ise ainda veio a se envolver, algum tempo depois, com o quarto filho do imperador Uda, Atsuyoshi, do qual teve uma filha, Nakatsukasa, que também figura entre os Sanjûrokkasen.

De Nakatsukasa também não se sabe o nome, apenas seu cognome derivado de um dos cargos ocupados por seu pai. Participou de várias competições e era admirada por seus pares por seu talento tanto em poesia quanto por tocar koto, similar ao de sua mãe. Trocou poemas com Tsurayuki e envolveu-se com vários nobres, tendo se casado com Minamoto no Saneakira, filho de Minamoto no Kintada (neto do imperador Kôkô), ambos também incluídos entre os Sanjûrokkasen. Tanto Saneakira quanto Kintada têm poucos poemas na Gosenshû e Shûishû. Kintada aparece no tópico de alguns poemas de Tsurayuki presentes na Shûish $\hat{u}$, sendo possível inferir que se conheciam.

Sakanoue no Korenori era descendente do general Sakanoue no Tamuramaro (758 - 811), apontado pelo imperador Kammu em 797 como seii taishôgun (征夷大 将軍), grande general apaziguador dos bárbaros, com a tarefa de subjugar os emishi, a qual completou em 801. Korenori foi alçado a Gon no shôjô (権少掾), secretário júnior, de Yamato em 908 e em 924 chegou a vice-governador de Kaga. Foi pai de Sakanoue no Mochiki, um dos Nashitsubo no gonin o qual, no entanto, não está entre os Sanjûrokkasen.

Minamoto no Muneyuki, neto de Kôkô Tennô, participou de diversas competições e é mencionado em Yamato Monogatari. Fujiwara no Okikaze, renomado músico, também era parte do meio literário da corte e foi responsável, em 951, por escrever poemas para a comemoração do aniversário de 50 anos da consorte do príncipe Sadayasu.

Ônakatomi no Yorimoto participou de várias competições e estava entre os escolhidos, dos quais constavam Tsurayuki, Mitsune e Korenori, a apresentarem poemas 
para a corte, em 907 (大井川行幸). Seu filho, Yoshinobu, também participou de diversas uta awase, além de ser apontado como um dos Nashitsubo no gonin (MURASE, 1959, p. 18).

Dos Nashitsubo no gonin, compiladores da Gosensh $\hat{u}$, Yoshinobu, Minamoto no Shitagô e Kiyohara no Motosuke estão entre os Sanjûrokkasen. Shitagô era renomado poeta e estudioso, tendo sido responsável pela organização da Wamyô Ruijû Shô (和 名類聚抄), uma espécie de dicionário japonês de caracteres chineses, sob ordens da filha do imperador Daigo, por volta de 934. Tanto Yoshinobu quanto Shitagô (Mochiki e Tokibumi) não incluíram seus poemas na Gosenshû. Motosuke, por sua vez, tem um poema na Gosenshû. Filho do renomado poeta Fukayabu, teve como filha Sei Shônagon.

Fujiwara no Atsutada era o terceiro filho do proeminente Sadaijin (Ministro da esquerda) Tokihira. Poeta admirado, aparece na Yamato Monogatari. Conhecia Ise e Nakatsukasa, pelo que é possível perceber através dos poemas 445 e 446, respectivamente de cada uma, acompanhados por notação, que trata da ocasião de convidá-las a recitar poemas nas rochas de uma cachoeira em Nishisakamoto, no Monte Hiei ${ }^{9}$.

Fujiwara no Asatada, quinto filho de Sadakata, era conhecido como Sanjô no Udaijin, Ministro da direita do terceiro distrito, pelo seu cargo, residindo na capital. Asatada, porém, chegou apenas ao cargo de Chûnagon, conselheiro médio.

Taira no Kanemori, tataraneto do imperador Kôkô e filho do príncipe Atsuyuki, recebeu sobrenome em 950, sendo retirado assim do registro da família imperial. Ocupou vários cargos, dentre os quais o de governador de Echizen. Renomado poeta, é famoso pela competição que travou com Mibu no Tadami, dentro da qual compuseram, cada um, poemas sobre o tema amor escondido com tal destreza, que o juiz apontado na ocasião não conseguiu determinar qual seria o melhor. Levada a dúvida ao imperador Murakami para solucionar o impasse, este apenas repetiu o poema de Kanemori, conferindo a este a vitória.

Fujiwara no Nakafumi ocupou vários cargos, dentre os quais o de governador de Kaga e de governador de Iga. Nakafumi teria conhecido alguns poetas da Sanjûrokkasen com os quais trocava poemas, como Yoshinobu e Motosuke. Como exemplo, encontramos os poemas 535 e 536 na Shûishû, respectivamente de Nakafumi e Yoshinobu. Segundo Mizugaki (2009), também teria trocado poemas com o próprio Kintô.

Kishi Joô era neta do imperador Daigo, filha do príncipe Shigeakira (quarto filho de Daigo) e de Fujiwara no Kanshi (segunda filha de Fujiwara no Tadahira). Em 948 tornou-se consorte do imperador Murakami (seu tio) e em 949 deu a luz a uma filha, princesa imperial Kishi (Kishi Naishinnô). Foi contemporânea de poetas como Shitagô e Yoshinobu, freqüentando os mesmo círculos literários.

Fujiwara no Takamitsu era o oitavo filho do Udaijin Morosuke (filho de Fujiwara no Tadahira) e da princesa imperial Gashi, filha do imperador Daigo. Ocupou vários

9 No original: “權中納言敦忠が西坂本の山庄の瀧の岩にかきつけ侍りける” (Shîish $\hat{u}, \quad$ in: Japanese Initiative Text). 
cargos na corte como o de Grande camareiro, jijû (侍従), e “Major-general”, shôshô (右 少将), desfrutando de certa popularidade na corte. Participou de competições, dentre as quais a uta awase realizada no palácio imperial em 960. Somente realizou seu desejo de se tornar monge em 961, no ano seguinte ao da morte de seu pai, quando abandonou a família (esposa e filha pequena) para subir o Monte Hiei e iniciar seu retiro (anunciando em 962 que não voltaria mais à cidade). A partir das cartas que trocara com a esposa, de nome desconhecido, da correspondência desta com sua cunhada Aimiya, e mais cartas de familiares preocupados, foi organizada a Tonomine shôshô monogatari (冬武 峰少将物語) pela ajudante da esposa de Takamitsu sob ordens desta, a fim de que não fosse logo esquecido por seus pares. Segundo Gatten (1998, p. 167), quando Takamitsu repentinamente se tornou monge, houve grande comoção e composição de diversos poemas.

Minamoto no Shigeyuki era descendente do imperador Seiwa, e chegou a ocupar vários cargos, como o de governador de Sagami. Participou de várias competições e era amigo de Kanemori e Saneakira. Também contemporânea de Kintô, Kodai no Kimi serviu na corte como dama camareira, onna kurôdo (女蔵人), do herdeiro aparente, o qual viria a se tornar o imperador Sanjô. Ela conviveu e trocou poemas com vários nobres poetas, como o próprio Kintô, do qual era amiga (MCCULLOUGH, 1980, p. 179).

Não obstante, dos trinta e seis poetas listados, dois não têm poemas nestas coletâneas: Sarumaru e Fujiwara no Motozane. Sobre Sarumaru, só no prefácio em chinês encontra-se uma menção a seu respeito ao tratar das composições de Ôtomo no Kuronoshi - os poemas de Ôtomo no Kuronoshi seguem os do ilustre Sarumaru -, que apesar de seus méritos, seu estilo é rude, como se um camponês estivesse descansando frente a uma árvore florida (MCCLLOUGH, 1985, p. 324). Todavia, o poema 215 na Kokinshû, apesar de constar como anônimo, somente com a indicação de que teria sido composto em uma uta awase do Príncipe Koresada em 893, lhe é atribuído na Ogura Hyakunin Isshu, de Fujiwara no Sadaie. Segundo Mostow (1996, p. 155), tal poema ainda aparece incluído na coleção de poemas de Michizane. Em relação à seleção de três poemas feita por Kintô como exemplares da obra de Sarumaru (Quadro 3.1), todos estão presentes na Kokinsh û, mas com a notação de autoria desconhecida,「よみ人し らず」. 
QUADRO 3: Poemas considerados como de autoria de Sarumaru por Fujiwara no Kintô

\begin{tabular}{|l|c|}
\hline POEMA NA SANJÛROKKASEN & $\begin{array}{c}\text { N. DO POEMA NA } \\
\text { KOKINSHÛ }\end{array}$ \\
\hline $\begin{array}{l}\text { をちこちのたづきもしらぬ山なかにおぼつかなくも } \\
\text { よぶどりかな }\end{array}$ & 29 \\
$\begin{array}{l}\text { Ochikochi no tazuki mo shiranu yama naka ni obotsukanaku } \\
\text { mo yobukodori kana }\end{array}$ & \\
\hline $\begin{array}{l}\text { ひぐらしのなきつるなへに日はくれぬと思ふは山の } \\
\text { かげぞありける }\end{array}$ & 204 \\
$\begin{array}{l}\text { Higurashi no nakitsuru nae ni hi wa kurenu to omou wa } \\
\text { yama no kage ni zo arikeru }\end{array}$ & \\
\hline $\begin{array}{l}\text { おく山に紅葉ふみわけなく鹿のこ总きく時ぞ秋は悲 } \\
\text { しき }\end{array}$ & 215 \\
$\begin{array}{l}\text { Okuyama ni momiji fumiwake naku shika no koe kiku toki } \\
\text { zo aki wa kanashiki }\end{array}$ & \\
\hline
\end{tabular}

Os poemas de Fujiwara no Motozane, por sua vez, só começaram a aparecer nas coletâneas imperiais a partir da Goshûishû (1086). O poeta participou da uta awase de 960, realizada no palácio imperial. Ocupou diversos cargos, dentre eles o de vice-governador de Tanba, em 966.

\section{Considerações finais: entre poetas lendários e conhecidos pares, uma lista pessoal?}

Dos Sanjûrokkasen, quatorze poetas estão presentes na Kokinshû, dentre os quais nobres responsáveis por sua compilação, Ki no Tomonori, Ki no Tsurayuki, Ôshikôchi no Mitsune e Mibu no Tadamine, nobres com os quais conviveram em círculos literários da corte, como Fujiwara no Kanesuke, e nobres que figuraram no imaginário social e que reverberam em contos como Ise Monogatari e Yamato Monogatari, como Ono no Komachi e Ariwara no Narihira.

Da geração posterior à Kokinsh $\hat{u}$, encontramos descendentes de notáveis como Mibu no Tadami e Nakatsukasa, e nomes consagrados como os Nashitsubo no gonin. Todavia, chama a atenção a ausência de dois deles, em particular a do filho 
de Ki no Tsurayuki, Ki no Tokibumi, não só por sua ascendência como também pelo prestígio aparentemente por ele mesmo conquistado como um dos Nashitsubo no gonin ${ }^{10}$.

Sobre a omissão de Fujiwara no Motozane, por não sabermos até que ponto Kintô foi capaz de imprimir sua visão na Shûishû, duas hipóteses podem ser levantadas: que foi cortado (ou não adicionado) na versão final editada pelo imperador Kazan, ou então que não chegou sequer a ser adicionado ao rascunho feito por Kintô, Shûishô, organizado por volta de 996 e 999 (HARRIES, 1980, p. 301), tendo este sido feito antes de sua ascensão como poeta na corte. Todavia, do pouco que se sabe de Motozane, teria trabalhado em Kaga por volta de 935, ocupando diversos cargos, culminando em 966 como vice-governador de Tanba, portanto, sua atividade como poeta teria ocorrido em meados do século X e, assim, anterior ou contemporânea ao Shûishô.

Quanto a Sarumaru, podemos conjecturar de dois modos: que se trata de uma figura mítica passada no imaginário de geração para geração, reforçada por sua presença no prefácio da Kokinsh $\hat{u}$, e, se de fato existiu, sua presença se perdeu na história oral ou, ainda, os registros sobre ele foram perdidos. A possibilidade de que seja mencionado por outro epíteto em registros conhecidos é difícil de ser verificada, uma vez que pouco resta do que é atribuído como sendo de sua autoria e, ao cruzar tais poemas, como o de número 5 da Ogura Hyakunin Isshu com o 215 da Kokinshû, só é possível encontrar a notação de autor desconhecido. No entanto, a coleção de poemas atribuídos a ele, Sarumaru Shû (猿丸集), data do final do século IX. Segundo Ohnuki-Tierney (1989, p. 52; 111), teóricos como Yanagita e Origuchi desenvolvem o argumento de que Sarumaru de fato se referia a "um número de monges poetas itinerantes que teriam formado um grupo chamado Sarumaru". Mostow (1996, p. 155) aponta que, dado o mistério que o cerca, em muitas ilustrações há a tendência de representá-lo com feições de macaco, em referência também ao nome que lhe é atribuído.

Se as coletâneas imperiais são regidas pela política do status e prestígio segundo a égide do imperador que a evoca, espera-se que as coletâneas e listas de poemas organizadas e selecionadas por um indivíduo reflitam não só parte desse jogo como também a mão de seu organizador. Nesse viés, um poeta com o status Fujiwara no Kintô provavelmente teria maior autonomia e autoridade para expor e impor suas escolhas, principalmente em se tratando de uma listagem sem caráter oficial. Tendo em vista suas desavenças com Kazan In na organização da Shûishû, deduz-se que de certa maneira era tenaz em suas seleções de poemas.

Destarte, a organização da lista dos poetas exímios é laureada pela relativa liberdade por não ter sido comissionada. Como produto de um projeto particular de Kintô, reflete assim seu diálogo com seu tempo e pares, ao passo que nos fornece algumas evidências sobre seu caráter como poeta e como autoridade na produção lírica da nobreza.

10 Gosenshû foi concluída por volta de seis anos após a morte de Tsurayuki, o que levanta a questão da participação de seu filho, Tokibumi, como continuidade de seu legado, seja por motivação própria de Tokibumi, seja por incentivo ou expectativa daqueles que conheceram ou admiravam Tsurayuki. 
Pelo menos oito dos Sanjûrokkasen foram contemporâneos de Fujiwara no Kintô, como Kodai no Kimi (小大君), que se tornou ativa nos círculos literários por volta de 979 . Assim, a lista corresponde principalmente ao período de juventude de Kintô, momento de aprendizado, no qual parte de sua compreensão como poeta e sua arte de compor encontra suas bases - é o imaginário dessa época, provavelmente até a primeira década do século XI, que, em certa medida, é refletido na seleção dos Sanjûrokkasen. Tendo em vista que essa lista foi organizada por volta do ano 1010, (MURASE, 1959; HARRIES, 1980, p. 312), Kintô provavelmente selecionou poetas que então continuavam a viver apenas no imaginário social e não mais entre seus pares, imortalizando-os no panteão dos grandes poetas.

\section{Referências bibliográficas}

ASAHI Nihon Rekishi Jinbutsu Jiten. Disponível em: http://www.kotobank.co.jp. Acessado: em junho de 2016.

BROWER, Robert \& MINER, Earl. Japanese court poetry. California: Stanford University Press, 1988.

GATTEN, Aileen. Fact, Fiction, and Heian Literary Prose: epistolary narration in Tonomine Shosho Monogatari. Monumenta Nipponica, v. 53, n. 2, p. 153-195, 1998.

HARRIES, Phillip. Personal Poetry Collections: their origin and development through the Heian Period. Monumenta Nipponica, v. 35, n. 3, p. 299-317, 1980.

HISAMATSU, Sen'ichi. Biographical dictionary of Japanese Literature. Tokyo: Kodansha International, 1982.

JAPANESE Initiative Text. University of Virginia Library. Disponível em: http://etext.lib. virginia.edu/japanese/, acessado em: julho de 2009.

KOKIN WAKASHÛ: The First Imperial Anthology of Japanese Poetry: with 'Tosa Nikki' and 'Shinsen Waka' / Translated and Annotated by Helen Craig McCullough. Stanford: Stanford University Press, 1985.

MCCULLOUGH, Helen Craig. Brocade by night: 'Kokin Wakashu' and the Court Style in Japanese Classical Poetry. Stanford: Stanford University Press, 1985.

MINER, Earl; ODAGIRI, Hiroko; MORRELL, Robert. The Princeton Companion to Classical Japanese Literature. New Jersey: Princeton University Press, 1988.

MOSTOW, Joshua S. Pictures of the Heart: The Hyakunin Isshu in Word and Image. Honolulu: University of Hawaii Press, 1996.

MURASAKI SHIKIBU. The diary of Lady Murasaki / tradução e introdução de Richard Bowring (Penguin classics). London; New York: Penguin, 1996.

MURASE, Toshio. A Study on the Life of Fujiwara-Kinto. Proceedings of the Faculty of Letters of Tokai University, v. 2, p. 1-46, 1959. 
OHNUKI-TIERNEY, Emiko. The Monkey as mirror: symbolic transformations in Japanese History and Ritual. Princeton: Princeton University Press, 1989.

SHIBUYA, Eiichi. (Kokugo - Kokubungaku) Kenkyushitsu. Disponível em: http://www. takachiho.ac.jp/ eshibuya/, acessado em: julho de 2009.

STRONG, Sarah. The Making of a Femme Fatale: Ono no Komachi in the Early Medieval Commentaries. Monumenta Nipponica, v. 49, n. 4, p. 391-412, 1994.

TAKAMORI, Akinori. Rekidai tennô jiten. Tokyo: PHP Kenkyûjo, 2008.

TAKAYANAGI, Mitsunaga; TAKEUCHI, Rizô. Kadokawa Nihonshi Jiten. Tokyo: Kadokawa, 1974.

TEELE, Nicholas. Rules for Poetic Elegance: Fujiwara no Kinto's Shinsen Zuino \& Waka Kubon. Monumenta Nipponica, v. 31, n. 2, p. 145-164, 1976.

TSUJI, Norio. Shuiwakashu no Man’yo uta. Review of Shinwa Women's College, v. 24, p.145, 1991.

WADA, Yoshikazu. Kakinomoto no Hitomaru no Kaminagara shishou nitsuite. Memoirs of the Fukui Institute of Technology, v. 36, p.83-92, 2006. 